\title{
INDEX TO VOLUME 2
}

Albus, J. S., See Kent \& Albus

Antigue, F., See Francois \& Antigue

Billingsley, J., See Naghdy, Billingsley \& Harrison

Camacho, M., See Davis \& Camacho

Camacho, M., See Davis \& Camacho

Davis, R. H., \& Camacho, M., The application of logic programming to the generation of paths for robots, 93-103

Davis, R. H., \& Camacho, M., The application of logic programming to the generation of plans for robots, 137-146

Devyanin, E. A., See Gurfinkel, Devyanin, Lensky, Mozhzhevelov, Formal'sky \& Shneider

Doi, H., See Fukada, Doi, Nagamine \& Inari

El Gindy, H. A., See Toussaint \& El Gindy

Fleck, J., Introduction of the industrial robot in Britain, 169-175

Formal'sky, A. M., See Gurfinkel, Devyanin, Lensky, Mozhzhevelov, Formal'sky \& Shneider

Francois, C., \& Artigue, F., Automated assembly by reference measurement, 197-201

Fukada, Y., Doi, H., Nagamine, K., \& Inari, T., Relationships-based recognition of structural industrial parts stacked in a bin, 147-154

Fu, K. S., Special computer architectures for image analysis, 27-31

Furuta, K., Kosuge, K., Yamano, O., \& Nosaki, K., Robust control of a robot manipulator with nonlinearity, 75-81

Gurfinkel, V. S., Devyanin, E. A., Lensky, A. V., Mozhzhevelov, S. B., Formal'sky, A. M., \& Schneider, A. Yu., Controlling a manipulator using sensory motor interaction, 155-159

Harrison, D., See Naghdy, Billingsley \& Harrison

Ikeda, J., See Sawano, Ikeda, Utsumi, Ohtani, Kirkuchi, \& Ito

Inari, T., See Fukada, Doi, Nagamine \& Inari

Inari, T., See Kuroda, Jitsumori \& Inari

Ito, Y., See Sawano, Ikeda, Utsumi, Ohtani, Kirkuchi, \& Ito

Jarvis, R. A., Application-oriented robotic vision-a review, 3-15

Jarvis, R. A., \& Oh, Y. L. Introduction to the special issue on robotic vision, 1

Jitsumori, A., See Kuroda, Jitsumori \& Inari

Karnik, A. M., \& Sinha, N. K., A direct approach to modeling an industrial robot from samples of input-output data, 161-167

Kent, Ernest W., \& Albus, James S. Servoed world models as interfaces between robot control systems and sensory data, 17-25

Kirkuchi, A., See Sawano, Ikeda, Utsumi, Ohtani, Kirkuchi, \& Ho

Kosuge, K., See Furata, Kosuge, Yamano \& Nosaki

Kuroda, S., Jitsumori, A., \& Inari, T., Ultrasonic imaging system for robots using an electronic scanning method, $47-53$

Lee, M. H., The three robot worlds-a view point (A review of the different goals of robotics research), 71-74

Lensky, A. V., See Gurfinkel, Devyanin, Lensky, Mozhzhevelov, Formal'sky \& Shneider

Matsuda, F., See Yamada, Matsuda, Tsuchida \& Ueda

Mozhzhevelov, S. B., See Gurfinkel, Devyanin, Lensky, Mozhzhevelov, Formal'sky \& Shneider

Nagamine, K., See Fukada, Doi, Nagamine \& Inari

Naghdy, F., Billingsley, J., \& Harrison, D., Simulation of human judgement in a robot-based adjustment system, 209-214

Nosaki, K., See Furuta, Kosuge, Yamano \& Nosaki 
Ohtani, Y., See Sawano, Ikeda, Utsumi, Ohtani, Kirkuchi \& Ito

Oh, Y. L., See Jarvis \& Oh

Ranky, P. G., Programming industrial robots in FMS (A survey with particular reference to off-line, high-level robot program generation using VAL, VAL-II, AML and MARTI), 87-92

Salter, R. M., Declarative modeling of symbolic continuous processes in a robot simulation system, 105-109

Sawano, S., Ikeda, J., Utsumi, N., Ohtani, Y., Kirkuchi, A., \& Ito, Y., A sealing robot system with visual seam tracking, 41-46

Sternberg, Stanley R., Parallel processing in machine vision, 33-40

Shivarov, N., \& Yanakiev, K., Automated manipulating system for an industrial robot for arc-welding, 203-207

Shneider, A Yu., See Gurfinkel, Devyanin, Lensky, Mozhzhevelov, Formal'sky \& Shneider

Sinha, N. K., See Kernik \& Sinha

Toussaint, G. T. \& El Gindy, H. A., Separation of two monotone polygons in linear time, 215-220

Tsuchida, N., See Yamada, Matsuda, Tsuchida \& Ueda

Ueda, M., See Yamada, Matsuda, Tsuchida \& Ueda

Utsumi, N., See Sawano, Ikeda, Utsumi, Ohtani, Kirkuchi \& Ito

Yamada, Y., Matsuda, F., Tsuchida, N. \& Ueda, M., Sensor control for moving objects, 83-86

Yamano, O., See Furuta, Kosuge, Yamano \& Nosaki

Yanakiev, K., See Shivarov \& Yanakiev 


\section{INDEX OF BOOKS REVIEWED IN VOLUME 2}

The name of the reviewer of the book is given in parentheses

Aleksander, I. \& Burnet, P. Reinventing Man: The Robot Becomes Reality. (A. M. ANDREw), 118

Aleksander, I. (Ed.) The International Robotics Yearbook. (J. Rose) 246

Brock, T. E. (Ed.) Proceedings of the Sixth British Robot Association annual conference. (A. M. ANDREW), 117

Coiffet, P., Robot Technology: Vol. 1: Modelling and Control. (M. W. THRING) 181

Coiffet, P. Robot Technology, Vol. 2. (M. W. THRING) 247

Hartley, J. Robots at Work: A Practical Guide for Engineers and Managers. (A. M. ANDREw) 118

Hayes-Roth, F., Waterman, D. A. \& Lenal, D. B. (Eds) Building Expert Systems. (J. Self) 119

Helmers, C. T. (Ed.) In the Beginning: The Breakthrough Discoveries as Reported in Robotics Age Magazine. (A. M. ANDREw) 118-119

Hicks, D. J. (Ed.) Semi-Custom IC Design and VLSI. (J. A. Esrom) 245

Isata 83 Proceedings. (P. G. RANKY) 120-121

Kogan, A. B. et al. (Eds) Problemy Neirokibernetiki. (E. Nicol_au) 179

Lasers in Manufacturing. Proceedings First International Conference. (M. W. THRING) 179-180

Lhote, F., Kauffmann, J.-M., Andre, P. \& Taillard, J.-P. Robot Components and Systems. (P. G. RANKY) 246

Makino, H. (Ed.) Proceedings of the Fourth International Conference on Assembly Automation. (M. W. Thring) 180-181

McLean, M. (Ed.) Mechatronics. (H. H. RosenBrock) 120

Microelectronics, Robotics and Jobs (OECD Report, ICCP No. 7). (H. H. RosenBROCK) 119

O'Shea, T. \& Eisenstadt, M. (Eds) Artificial Intelligence: Tools, Techniques, and Applications. (A. M. ANDREw) 177

Sadamoto, K. (Ed.) Mechanical Hands-Mllustrated. (A. M. ANDREw) 117

The Software Catalog, Microcomputers. (J. A. Estom) 245

The Software Catalog, Minicomputers. (J. A. EsRom) 245

United Nations Economic and Social Council, Production and Use of Industrial Robots, Part 1. (P. ESROM) 177-178

White, J. A. (Ed.) Automation in Warehousing. Proceedings of the Fifth International Conference, Georgia, USA. (M. W. TRING) 178-179 


\section{Notes for Contributors}

1. Manuscripts should preferably be written in English, but papers in French and German will also be accepted. All manuscripts will be referred to acknowledged experts in the subject. Only those receiving favourable recommendations from the referees will be accepted for publication. Manuscripts may be sent to any Board member, any Deputy Editor or the Editor.

2. Typescripts should be double spaced, on one side of good grade paper, allowing a reasonable left-hand margin. An original and two copies should be submitted with the author's full postal address, position and affiliations.

3. A short abstract of about 80 words should precede the main text. List of symbols: A typewritten list of any special symbols should be submitted with the manuscript. The list should not define the symbols mathematically, but should serve to identify them typographically. The list will not appear in print, but is essential to help the typesetter and to avoid costly correction in proof.

4. One copy of photographs, prints or transparencies of good quality and unmarked should be submitted. Where lines or lettering are to appear on the photograph, an additional print should be supplied appropriately marked. Each should have, lightly written on the back, the author's name, the figure number and an indication of which is the top of the picture.

5. One copy of each line diagram should be submitted at approximately twice final size and unlettered. Diagrams must be drawn in indian ink on plain white or transparent paper. A second copy should be supplied with lettering included. The author's name and the figure number should be written on this copy. Figures should be numbered consecutively, with arabic numerals, have descriptive captions, and be mentioned in the text. The correct position for each figure should be indicated in the margin of the manuscript.

6. Tables should be typewritten on separate sheets. Avoid, where possible, very wide tables. Number tables consecutively with roman numerals. Each should have a brief heading. Exceptionally lengthy tables may be summarized for publication with a note that copies of details can be obtained from the authors.

7. Equations: Wherever possible, mathematical equations should be typewritten, with subscripts and superscripts clearly indicated. The printer will set all mathematical symbols in italics unless otherwise indicated; symbols or letters to be set in roman (upright) type should be encircled in pencil, while bold letters should be shown by a wavy underline.

8. References: In the text, references are indicated by superior arabic numbers (without brackets), and should be confined to publish work that is directly pertinent. References should be listed at the end of the paper in numerical order. Authors' initials should precede their names; cited article titles should be quoted in full, enclosed in quotation marks; and abbreviations of journal names should follow the style of Chemical Abstracts or Physical Abstracts, and be underlined for italics: P.W. Anderson, "More is different" Science 177, 393 (1972) C.V. Negoita, Fuzzy Systems (Abacus Press, Tunbridge Wells, UK, 1980)

Citations such as 'personal communication', 'unpublished work', etc., are not acceptable as numbered references but can be included in parenthesis in the text. Do not use summaries as references.

9. Proofs: Page proofs will be sent to authors for correction, for return within 48 hours by airmail. Correction to proofs should be restricted to printers' errors only. Authors are entitled to 25 offprints of their article free of charge. Additional offprints may be purchased if they are ordered on the form sent with the proofs.

10. Manuscripts, whether accepted or rejected, will not be returned to the authors.

11. Submission of an article will be taken to imply that it has not been previously published and that it is not on offer to any other publisher. 


\section{CONTENTS}

Reports and Surveys (Education and Training in Robotics, Microcomputers-The QL Saga, Models of Remembrance, New Products and Projects, Robot Competitions, Robot Slaves, Robotics Worldwide, Superbrains) R. H. Rudall (U.K.)

Real-time cooperative interaction between structured-light and refiectance ranging for robot guidance, Ernest W. Kent, Thomas Wheatley and Marilyn Nashman (U.S.A.)

Robots and mining: the implications for Australian industry in the 1980's, M. Kassler (Australia)

An efficient numerical approach for calculating the inverse kinematics for robot manipulators, Jadran Lenarcic (Yugoslavia)

The effect of information technology on manufacturing, Professor $I$.

Aleksander (U.K.)

Towards automatic software generation, B. H. Rudall (U.K.)

Changing needs of industrial and commercial education and training, R. G. Taylor (U.K.)

A fuzxy model for learning in automata, Ashoke Kumar Datta (India)

Obituary

Special Feature

Conference Reports

Book Reviews

Announcements 